TITLE:

\title{
Coordination characteristics of trivalent lanthanides and actinides in molten hydrate salts of $\mathrm{Ca}(\mathrm{NO} 3) 2$ and $\mathrm{CaCl} 2$
}

\section{$\operatorname{AUTHOR}(\mathrm{S}):$}

Fujii, Toshiyuki; Okude, Genki; Uehara, Akihiro;

Sekimoto, Shun; Hayashi, Hirokazu; Akabori,

Mitsuo; Minato, Kazuo; Yamana, Hajimu

\section{CITATION:}

Fujii, Toshiyuki ... [et al]. Coordination characteristics of trivalent lanthanides and actinides in molten hydrate salts of $\mathrm{Ca}(\mathrm{NO} 3) 2$ and $\mathrm{CaCl} 2$. Journal of Radioanalytical and Nuclear Chemistry 2011, 288(1): 181-187

ISSUE DATE:

2011-04

URL:

http://hdl.handle.net/2433/141852

\section{RIGHT:}

The final publication is available at www.springerlink.com; この論文は 出版社版でありません。引用の際には出版社版をご確認ご利用くださ $\omega_{\circ}$; This is not the published version. Please cite only the published version. 
Short Communication

Coordination characteristics of trivalent lanthanides and actinides in molten hydrate salts of $\mathrm{Ca}\left(\mathrm{NO}_{3}\right)_{2}$ and $\mathrm{CaCl}_{2}$

Toshiyuki Fujii, ${ }^{1}$ Genki Okude, ${ }^{1,2}$ Akihiro Uehara, ${ }^{1}$ Shun Sekimoto, ${ }^{1}$ Hirokazu Hayashi, ${ }^{3}$ Mitsuo Akabori, ${ }^{3}$ Kazuo Minato, ${ }^{3}$ and Hajimu Yamana ${ }^{1}$

1 Division of Nuclear Engineering Science, Research Reactor Institute, Kyoto University, 2-1010, Asashiro Nishi, Kumatori, Sennan, Osaka, 590-0494, Japan

2 Graduate School of Engineering, Kyoto University, Kyoto daigaku-Katsura, Nishikyo-ku, Kyoto 615-8530, Japan

3 Nuclear Science and Engineering Directorate, Japan Atomic Energy Agency, Tokai-mura, Ibaraki-ken 319-1195, Japan

*Author to whom correspondence should be addressed tosiyuki@rri.kyoto-u.ac.jp TEL: +81-724-51-2469, FAX: +81-724-51-2634

E-mail: tosiyuki@rri.kyoto-u.ac.jp 


\section{Abstract}

Distribution behavior of $\mathrm{Ce}(\mathrm{III}), \mathrm{Am}(\mathrm{III})$, and $\mathrm{Cm}(\mathrm{III})$ between tri-n-butyl phosphate solution and molten calcium nitrate hydrate $\mathrm{Ca}\left(\mathrm{NO}_{3}\right)_{2} \cdot R \mathrm{H}_{2} \mathrm{O}$ or molten calcium chloride hydrate $\mathrm{CaCl}_{2} \cdot R \mathrm{H}_{2} \mathrm{O}$ was studied radiochemically. In $\mathrm{Ca}\left(\mathrm{NO}_{3}\right)_{2} \cdot R \mathrm{H}_{2} \mathrm{O}$ systems, maximum separation factors of $\mathrm{Ce}$ and $\mathrm{Cm}$ to $\mathrm{Am}$ were observed to be $12(\mathrm{Ce} / \mathrm{Am})$ and $1.7(\mathrm{Cm} / \mathrm{Am})$. The distribution ratios of these elements increased with the decrease of water activity in the hydrates, and the extractabilities at the water deficient region was less sensitive compared to those at the water abundant region. This trend was similar to the coordination circumstance change observed in electronic absorption spectra of $\mathrm{Nd}(\mathrm{III})$ in the hydrates.

Keywords

Americium $\cdot$ Curium $\cdot$ Hydrate salt $\cdot$ Extraction $\cdot$ Activity 


\section{Introduction}

Extraction of lanthanides and actinides in molten hydrate salts (generally called "hydrate melts") by an organic solution of tri- $n$-butyl phosphate (TBP) has been investigated for $\mathrm{Ca}\left(\mathrm{NO}_{3}\right)_{2} \cdot 4 \mathrm{H}_{2} \mathrm{O}$ [1-7], $\mathrm{Mg}\left(\mathrm{NO}_{3}\right)_{2} \cdot 6 \mathrm{H}_{2} \mathrm{O}$ [2], and $\mathrm{Mn}\left(\mathrm{NO}_{3}\right)_{2} \cdot 6 \mathrm{H}_{2} \mathrm{O}$ [8] media. A typical PUREX system $\left(\mathrm{HNO}_{3}\right.$-TBP system) shows low extractability for trivalent lanthanides and actinides, while using hydrate melts as the inorganic phase gives higher extractability of these elements. This is attributed to the enhanced chemical activities of nitrates due to the water deficiency of the system. The extractability is equivalent to a PUREX system with highly concentrated $\mathrm{HNO}_{3}$ solutions $[9,10]$. The results have attracted technological interests for the purpose of recovering and separating lanthanides as fission products and trivalent actinides such as $\mathrm{Am}^{3+}$ and $\mathrm{Cm}^{3+}$ from high level radioactive wastes (HLLW) generated in the nuclear fuel cycle.

Beyond the HLLW technological interest, chemical behavior of trivalent lanthanides and actinides in hydrate melts is additional specific interest, especially, the coordination chemistry of f-elements in concentrated electrolytes. Cations, anions, and water molecules in hydrate melts contact each other continuously by forming a quasi-lattice structure [11]. A solute cation, e.g., trivalent lanthanide or actinide, in a hydrate melt is surrounded by anions and water molecules which are contacted by cations of the hydrate melt matrix. The mean activity coefficient of salts is much larger than unity [6], while the activity coefficient of water is much smaller than unity $[6,12]$, and they are drastically changed by changing water content. The specific coordination circumstance of solutes in the hydrate melts would make the chemical behavior of solute cation different from that in the usual aqueous solutions.

In the present study, we investigated the extraction distribution of trivalent $\mathrm{Eu}$, 
Am, and $\mathrm{Cm}$ between $\mathrm{Ca}\left(\mathrm{NO}_{3}\right)_{2} \cdot 4 \mathrm{H}_{2} \mathrm{O}$ and PUREX solvents (mixtures of TBP and $n$-dodecane). The extraction distribution of $\mathrm{Am}$ and $\mathrm{Eu}$ between $\mathrm{CaCl}_{2} \cdot 6 \mathrm{H}_{2} \mathrm{O}$ and PUREX solvents was studied for comparison. Additional information on the coordination circumstance was obtained via the $f-f$ hypersensitive transition of $\mathrm{Nd}(\mathrm{III})$ in the melts.

\section{Experimental}

\section{Solvent extraction}

All chemicals including $\mathrm{Ca}\left(\mathrm{NO}_{3}\right)_{2} \cdot 4 \mathrm{H}_{2} \mathrm{O}$ and $\mathrm{CaCl}_{2} \cdot 6 \mathrm{H}_{2} \mathrm{O}$ were reagent grade from Wako Pure Chemical Industries, Ltd., and were used without further purification. The nitric acid solution containing ${ }^{243} \mathrm{Am},{ }^{244} \mathrm{Cm}(\sim 100 \mathrm{kBq}$, respectively) was prepared and this was once evaporated to dryness. A few $\mathrm{dm}^{-3}(\mathrm{~mL})$ of pure water was added and evaporated again. This process was repeated several times to remove nitric acid completely. The final residue, ${ }^{243} \mathrm{Am}\left(\mathrm{NO}_{3}\right)_{3}$ and ${ }^{244} \mathrm{Cm}\left(\mathrm{NO}_{3}\right)_{3}$ were dissolved into the molten $\mathrm{Ca}\left(\mathrm{NO}_{3}\right)_{2} \cdot 4 \mathrm{H}_{2} \mathrm{O}$. An organic solution of $0.004 \mathrm{~mol} \mathrm{dm}^{-3}$ (M) TBP diluted with $n$-dodecane (PUREX solvent) was prepared. This organic solution was pre-equilibrated with fresh $\mathrm{Ca}\left(\mathrm{NO}_{3}\right)_{2} \cdot 4 \mathrm{H}_{2} \mathrm{O}$ at room temperature.

Fifteen $\mathrm{mL}$ of the hydrate melt and $15 \mathrm{~mL}$ of the PUREX solvent were contacted by magnetic stirring in a glass centrifuge tube. The extraction was performed in a water bath at $343 \mathrm{~K}$. Extraction equilibrium was attained in 2 hours. Under the equilibrium, two phases were separated by centrifugation and weighed portions of both phases were taken for $\gamma$-spectrometry to determine the distribution ratios $(D)$ of ${ }^{243} \mathrm{Am}$ and ${ }^{244} \mathrm{Cm}$. Intensities of $\gamma$ rays $\left(75 \mathrm{keV}\right.$ and $43 \mathrm{keV}$ for ${ }^{243} \mathrm{Am}$ and ${ }^{244} \mathrm{Cm}$, respectively) were analyzed. The self-shielding effect, which is the loss of transmittance of the $\gamma$ rays 
inside samples, was corrected as shown in our previous study [7]. All quantifications of hydrate melts and PUREX solvents were performed gravimetrically to avoid the large errors associated with volumetric treatment. The gravimetric radioactivities were converted to volumetric radioactivities using the density of solutions, in which literature values [13] or densities measured by employing a picnometer were used. Then, weighed TBP was added to the glass centrifuge tube to increase its molarity in the organic phase, and the same procedure was repeated. The extraction experiments with [TBP] ranging from 0.004 to $0.47 \mathrm{M}$ were performed. Since $\mathrm{Eu}$ is a $4 f$ element having similar ionic radius compared with those of Am and $\mathrm{Cm}$ [14], the same extraction experiment was performed with a radioactive tracer ${ }^{152} \mathrm{Eu} . D$ was determined from the $\gamma$-ray counts at $121.8 \mathrm{keV}$.

A similar extraction experiment of ${ }^{243} \mathrm{Am}$ was performed for hydrated $\mathrm{CaCl}_{2}$ medium. A portion of concentrated $\mathrm{HCl}$ was added to a dried ${ }^{243} \mathrm{Am}\left(\mathrm{NO}_{3}\right)_{3}$ to convert its chemical form to be ${ }^{243} \mathrm{AmCl}_{3}$, then the solution was evaporated to dryness. This was dissolved in molten $\mathrm{CaCl}_{2} \cdot 6 \mathrm{H}_{2} \mathrm{O}$. An organic solution of $0.1 \mathrm{M}$ TBP diluted with $n$-dodecane was prepared. This organic solution was pre-equilibrated with fresh $\mathrm{CaCl}_{2} \cdot 6 \mathrm{H}_{2} \mathrm{O}$ at room temperature. The extraction procedure was the same with the $\mathrm{Ca}\left(\mathrm{NO}_{3}\right)_{2} \cdot 4 \mathrm{H}_{2} \mathrm{O}$ case. By adding weighed water into the system to increase water content, the extraction experiments with $\mathrm{CaCl}_{2} \cdot \mathrm{RH}_{2} \mathrm{O}$ ranging from $R=6$ to 10 were performed at $343 \mathrm{~K}$. In order to know the extraction stoichiometry, $0.007 \mathrm{M} \mathrm{EuCl}_{3}$ dissolved in $\mathrm{CaCl}_{2} \cdot 6 \mathrm{H}_{2} \mathrm{O}$ was extracted at $343 \mathrm{~K}$ by PUREX solvents including 0.1-0.3 $\mathrm{M}$ TBP. The extracted $\mathrm{Eu}$ and $\mathrm{Ca}$ in the organic phase were stripped into a diluted $\mathrm{HCl}$ and the concentrations of $\mathrm{Eu}$ and $\mathrm{Ca}$ were analyzed by ICP-AES (ICPS-1000TR, Shimadzu). [Eu] and [Ca] in the equilibrated $\mathrm{CaCl}_{2} \cdot R \mathrm{H}_{2} \mathrm{O}$ phase were also analyzed. 


\section{Visible absorption spectrophotometry}

The $f$ - $f$ hypersensitive transition, ${ }^{4} G_{5 / 2}, \leftarrow{ }^{4} I_{9 / 2}$, of $\mathrm{Nd}$ was analyzed by visible absorption spectrophotometry. $\mathrm{Ca}\left(\mathrm{NO}_{3}\right)_{2} \cdot R \mathrm{H}_{2} \mathrm{O} \quad(R=3.4-15)$ and $\mathrm{CaCl}_{2} \cdot R \mathrm{H}_{2} \mathrm{O} \quad(\mathrm{R}=5.7-15)$ containing $\mathrm{Nd}$ with $[\mathrm{Ca}] /[\mathrm{Nd}] \sim 1000$ were prepared. $0.1 \mathrm{M} \mathrm{HClO}_{4}, 0.01 \mathrm{M} \mathrm{HNO}_{3}$, and $0.01 \mathrm{M} \mathrm{HCl}$ solutions containing $\sim 0.01 \mathrm{M} \mathrm{Nd}$ were also prepared. [Nd] was determined by ICP-MS (HP-4500, Hewlett Packard). Each sample was transferred into a quartz cell and the absorption spectrum from 560 to $600 \mathrm{~nm}$ was measured at $0.1 \mathrm{~nm}$ interval by using an absorption spectrophotometer (UV-3100PC, Shimadzu). All measurements were performed at room temperature. In order to evaluate the oscillator strength, the refractive index of samples at room temperature was determined by using a refractometer (Fisher Scientific).

\section{Results and discussion}

Extraction behavior of Eu, $\mathrm{Am}$, and $\mathrm{Cm}$ in $\mathrm{Ca}\left(\mathrm{NO}_{3}\right)_{2}$ hydrate melt by $\mathrm{TBP}$

The extraction reaction of trivalent lanthanides and actinides $\left(\mathrm{M}^{3+}\right)$ in the PUREX system can be written [15],

$$
\mathrm{M}^{3+}+3 \mathrm{NO}_{3}^{-}+3 \mathrm{TBP} \rightleftarrows \mathrm{M}\left(\mathrm{NO}_{3}\right)_{3} \cdot 3 \mathrm{TBP}
$$

It is natural that the distribution of $\mathrm{M}\left(D_{\mathrm{M}}\right)$ increases with the decrease of water content $R$ of $\mathrm{Ca}\left(\mathrm{NO}_{3}\right)_{2} \cdot R \mathrm{H}_{2} \mathrm{O}$ by depressing the hydration to $\mathrm{M}$. In the present study, the water activity, $a_{\mathrm{H}_{2} \mathrm{O}}$, is used as the representative of water deficiency. $a_{\mathrm{H}_{2} \mathrm{O}}$ is shown in Fig. 1 as a function of $R$ of $\mathrm{Ca}\left(\mathrm{NO}_{3}\right)_{2} \cdot R \mathrm{H}_{2} \mathrm{O}$. Since $a_{\mathrm{H}_{2} \mathrm{O}}$ of concentrated $\mathrm{Ca}\left(\mathrm{NO}_{3}\right)_{2}$ is not 
available [12], the $a_{\mathrm{H}_{2} \mathrm{O}}$ values in $\mathrm{Ca}\left(\mathrm{NO}_{3}\right)_{2}$ hydrate melts were evaluated in the present study by using an electric hygrometer (Novasina IC-500, AW-LAB). Small $a_{\mathrm{H}_{2} \mathrm{O}}$ can be seen at the water deficient region corresponding to hydrate melts. $D_{\mathrm{Eu}}, D_{\mathrm{Am}}$, and $D_{\mathrm{Cm}}$ obtained in our previous study [6,7] are shown in Fig 2a as functions of $a_{\mathrm{H}_{2} \mathrm{O}}$ newly estimated in the present study. The ionic radii of $\mathrm{Eu}^{3+}, \mathrm{Am}^{3+}$, and $\mathrm{Cm}^{3+}$ of 6-coordination in crystals [14] are similar but are in the order $\mathrm{Am}^{3+}>\mathrm{Cm}^{3+}>\mathrm{Eu}^{3+}$. The $D$ values are in the same order. The $D$ values increase with the decrease of $a_{\mathrm{H}_{2} \mathrm{O}}$ and $\log D>1$ can be achieved at the smaller $\log a_{\mathrm{H}_{2} \mathrm{O}}$ region. In this region, the extractability of Eu turned out to be smaller than that of Am and $\mathrm{Cm}$. This is due to the inflection of $\log D$ vs. $\log a_{\mathrm{H}_{2} \mathrm{O}}$ at $c a$. -0.33 for lanthanides [6] and ca. -0.4 for actinides [7]. This extraction trend change has been reported to be a coordination circumstance change of lanthanides and actinides in the $\mathrm{Ca}\left(\mathrm{NO}_{3}\right)_{2}$ hydrate melt [6]. The degree of the inflection is clearer for Eu than for Am and $\mathrm{Cm}$. This may be attributable to different physicochemical properties between $4 f$-orbitals and $5 f$-orbitals.

The $D$ values are shown in Fig. $2 \mathrm{~b}$ as functions of [TBP]. The slopes of $\log D$ vs. $\log [\mathrm{TBP}]$ were found to be 3 at small [TBP] region. This proves the validity of stoichiometry shown in reaction 1 for the hydrated $\mathrm{Ca}\left(\mathrm{NO}_{3}\right)_{2}$ system. The slope is moderated to be 2 with the increase of [TBP]. This is because the consumption of free TBP occurs by the extraction of $\mathrm{Ca}$ [4]. Though the coextraction of Ca occurs, the extractability of trivalent $f$-elements is improved to be $\log D>2$ at high [TBP] region.

The separation factors compared to Am, $D_{\mathrm{Eu}} / D_{\mathrm{Am}}$ and $D_{\mathrm{Cm}} / D_{\mathrm{Am}}$, are shown in Fig. $3 \mathrm{a}$ and $3 \mathrm{~b}$ as functions of $a_{\mathrm{H}_{2} \mathrm{O}}$ and [TBP]. As a maximum separation factor shown 
in Fig 3a, $D_{\mathrm{Eu}} / D_{\mathrm{Am}}=6.6$ was achieved at $\log a_{\mathrm{H}_{2} \mathrm{O}} \sim-0.25(R \sim 7)$, while $D_{\mathrm{Eu}} / D_{\mathrm{Am}}=$ 1.4 was achieved at $\log a_{\mathrm{H}_{2} \mathrm{O}} \sim-0.40(R \sim 5)$. The $D_{\mathrm{Eu}} / D_{\mathrm{Am}}$ value decreased to 1.1 at the water abundant region. The dependence of separation factor on [TBP] was not found for $D_{\mathrm{Cm}} / D_{\mathrm{Am}}$ which was ranged in 1.6-1.7 (Fig $3 \mathrm{~b}$ ). $D_{\mathrm{Eu}} / D_{\mathrm{Am}}$ increased with the decrease of [TBP] which reached to 12 , but their extractability was small as $\log D<-1$ (see Fig. $2 \mathrm{~b})$. The separation factor $D_{\mathrm{Eu}} / D_{\mathrm{Am}}$ was reported to be $8.7-84$ for an extraction system with an extractant TPEN ( $N, N, N^{\prime}, N^{\prime}$-tetrakis(2-methylpyridyl)-ethylenediamine) [16] and 960-7900 for a system with Cyanex 301 (bis(2,4,4-trimethylpentyl)dithiophosphinic acid) [17]. Our results would be too small on the viewpoint of Eu/Am separation. The separation factor $D_{\mathrm{Eu}} / D_{\mathrm{Am}}$ was reported to be $1.25-1.78$ for several complexing reagents [15,18, and references therein]. Our result $D_{\mathrm{Eu}} / D_{\mathrm{Am}} \sim 1.7$ showed a high value in the reported range, though the typical extractant TBP was used. Water deficient media may enhance the difference of chemical activities between Am and $\mathrm{Cm}$.

Extraction behavior of Am in $\mathrm{CaCl}_{2}$ hydrate melt by $\mathrm{TBP}$

The water activity $a_{\mathrm{H}_{2} \mathrm{O}}$ in $\mathrm{CaCl}_{2} \cdot 6 \mathrm{H}_{2} \mathrm{O}$ is almost the same with that in $\mathrm{Ca}\left(\mathrm{NO}_{3}\right)_{2} \cdot 4 \mathrm{H}_{2} \mathrm{O}$

(Fig. 1). The extraction behavior of trivalent $f$-elements in $\mathrm{CaCl}_{2}$ hydrate melts by TBP therefore is of interest. $D_{\mathrm{Am}}$ obtained is shown in Fig. 4 a as functions of $a_{\mathrm{H}_{2} \mathrm{O}}$. Low extractability of $\mathrm{Am}$ in the $\mathrm{CaCl}_{2}$ hydrate melt system is natural by considering the small $D$ values of trivalent $f$-elements reported for HCl-TBP systems [19,20]. Though [TBP] was 5 times larger than that of the $\mathrm{Ca}\left(\mathrm{NO}_{3}\right)_{2}$ case, $D_{\text {Am }}$ was found to be $\sim 100$ times smaller. Inflection of $\log D v s . \log a_{\mathrm{H}_{2} \mathrm{O}}$ at $c a$. -0.40 was also seen and its degree 
looks larger than that of the $\mathrm{Ca}\left(\mathrm{NO}_{3}\right)_{2}$ case.

In order to know the extraction stoichiometry, dependence of $D_{\mathrm{Eu}}$ on [TBP] was studied. The results are shown in Fig. 5. In the [TBP] region less than $0.1 \mathrm{M}$, the extraction of Ca was negligibly small. The consumption of TBP by the extraction of Ca was found to increase with $[\mathrm{TBP}]$, and at $[\mathrm{TBP}]=0.1 \mathrm{M}, 3 \%$ of TBP was consumed. The slope of $\log D_{\mathrm{Eu}} v s . \log$ [TBP] showed 3 at small [TBP] region, and hence, the extracted species would be $\mathrm{EuCl}_{3} \cdot 3 \mathrm{TBP}$.

Dependence of $D_{\mathrm{M}}$ on water activity

The extraction reaction 1 can be rewritten,

$$
\mathrm{M}\left(\mathrm{H}_{2} \mathrm{O}\right)_{\mathrm{m}}{ }^{3+}+3 \mathrm{X}^{-}+3 \mathrm{TBP} \rightleftarrows \mathrm{MX}_{3} \cdot 3 \mathrm{TBP}+m \mathrm{H}_{2} \mathrm{O}
$$

where $\mathrm{X}^{-}$represents $\mathrm{NO}_{3}{ }^{-}$or $\mathrm{Cl}^{-}$. The stability constant $K_{\mathrm{ex}}$ of this reaction is,

$$
K_{\mathrm{ex}}=\frac{\gamma_{\mathrm{MX}_{3} \cdot 3 \mathrm{TBP}}\left[\mathrm{MX}_{3} \cdot 3 \mathrm{TBP}\right] a_{\mathrm{H}_{2} \mathrm{O}}{ }^{\mathrm{m}}}{\gamma_{{\mathrm{M}\left(\mathrm{H}_{2} \mathrm{O}\right)_{\mathrm{m}}}^{3+}}\left[\mathrm{M}\left(\mathrm{H}_{2} \mathrm{O}\right)_{\mathrm{m}}{ }^{3+}\right] \gamma_{\mathrm{X}^{-}}{ }^{3}\left[\mathrm{X}^{-}\right]^{3} a_{\mathrm{TBP}}{ }^{3}}
$$

Because of $\left[\mathrm{MX}_{3} \cdot 3 \mathrm{TBP}\right] /\left[\mathrm{M}\left(\mathrm{H}_{2} \mathrm{O}\right)_{\mathrm{m}}{ }^{3+}\right]=D_{\mathrm{M}}$ and $\gamma_{{\mathrm{M}\left(\mathrm{H}_{2} \mathrm{O}\right)_{\mathrm{m}}}^{3+}} \gamma_{\mathrm{X}^{-}}{ }^{3}=\gamma_{\mathrm{MX}_{3}}{ }^{4}$, Eq. 3 is rewritten,

$$
K_{\mathrm{ex}}=\frac{\gamma_{\mathrm{MX}_{3} \cdot 3 \mathrm{TBP}} D_{\mathrm{M}} a_{\mathrm{H}_{2} \mathrm{O}}{ }^{\mathrm{m}}}{\gamma_{\mathrm{MX}_{3}}{ }^{4}\left[\mathrm{X}^{-}\right]^{3} a_{\mathrm{TBP}}{ }^{3}}
$$

Logarithm of $D_{\mathrm{M}}$ is hence,

$$
\begin{aligned}
\log D_{\mathrm{M}} & =\log K_{\mathrm{ex}}+4 \log \gamma_{\mathrm{MX}_{3}}+3 \log \left[\mathrm{X}^{-}\right]+3 \log a_{\mathrm{TBP}} \\
& -\log \gamma_{\mathrm{MX}_{3} \cdot 3 \mathrm{TBP}}-m \log a_{\mathrm{H}_{2} \mathrm{O}}
\end{aligned}
$$


For the experiments with constant $[\mathrm{TBP}]=0.02 \mathrm{M}$ for hydrated $\mathrm{Ca}\left(\mathrm{NO}_{3}\right)_{2}$ systems and with $[\mathrm{TBP}]=0.1 \mathrm{M}$ for hydrated $\mathrm{CaCl}_{2}$ systems, $\gamma$ and $a$ of species in the organic phases $\left(\gamma_{\mathrm{MX}_{3} \cdot 3 \mathrm{TBP}}\right.$ and $\left.a_{\mathrm{TBP}}\right)$ can possibly be treated as constants. In Eq. 5, (log $K_{\mathrm{ex}}+3$ $\left.\log a_{\mathrm{TBP}}-\log \gamma_{\mathrm{MX}_{3} \cdot 3 \mathrm{TBP}}\right)$ is treated as a constant value.

$$
\frac{1}{4}\left(\log D_{\mathrm{M}}-3 \log \left[\mathrm{X}^{-}\right]\right)=-\frac{m}{4} \log a_{\mathrm{H}_{2} \mathrm{O}}+\log \gamma_{\mathrm{MX}_{3}}+\text { Const. }
$$

$\frac{1}{4}\left(\log D_{\mathrm{Am}}-3 \log \left[\mathrm{X}^{-}\right]\right)$is shown in Fig. $4 \mathrm{~b}$ as functions of $\log a_{\mathrm{H}_{2} \mathrm{O}}$. The relationship $\frac{1}{4}\left(\log D_{\mathrm{Am}}-3 \log \left[\mathrm{X}^{-}\right]\right) v s . \log a_{\mathrm{H}_{2} \mathrm{O}}$ shows a similar inflection property with Fig. 4a. This means that the correction of $D_{\mathrm{M}}$ by $\left[\mathrm{X}^{-}\right]$is not the origin of this inflection. According to Eq. 6, the breakdown of the linear relation of $\frac{1}{4}\left(\log D_{\mathrm{M}}-3 \log \left[\mathrm{X}^{-}\right]\right) v s$. $\log a_{\mathrm{H}_{2} \mathrm{O}}$ would be due to a specific change in $\gamma_{\mathrm{MX}_{3}}$.

Variation of $\gamma_{\mathrm{Mx}_{3}}$ results from the coordination circumstance change of $\mathrm{M}^{3+}$ in hydrate melts with various water contents. In order to know it, electronic absorption spectra of $\mathrm{Nd}^{3+}$ in $\mathrm{Ca}\left(\mathrm{NO}_{3}\right)_{2} \cdot R \mathrm{H}_{2} \mathrm{O}$ and $\mathrm{CaCl}_{2} \cdot R \mathrm{H}_{2} \mathrm{O}$ were measured. The electric dipole transitions between $f$-orbitals that show abnormal variations in intensity are classified as hypersensitive transitions [21]. These variations are attributable to the action of an inhomogeneous electromagnetic field from the surrounding medium. In the case of neodymium, transitions from the ground level ${ }^{4} I_{9 / 2}$ to excited levels of ${ }^{2} G_{7 / 2}$ and ${ }^{4} G_{5 / 2}$, which are abbreviated as ${ }^{4} G_{5 / 2},{ }^{2} G_{7 / 2} \leftarrow{ }^{4} I_{9 / 2}$, are sensitive to the coordination 
circumstances, and they are commonly used to examine the coordination of $\mathrm{Nd}^{3+}[21]$. The transition ${ }^{4} G_{5 / 2} \leftarrow{ }^{4} I_{9 / 2}$ is the hypersensitive transition, which is accompanied by and overlapped with a less intensive non-hypersensitive transition to the level ${ }^{2} G_{7 / 2}$. The information on coordination environment of $\mathrm{Nd}^{3+}$ would be helpful to understand that of trivalent lanthanides and actinides having similar ionic radii.

The measured spectra of the hypersensitive transition are shown in Fig. 6a and 6b. The peak position of ${ }^{4} G_{5 / 2} \leftarrow{ }^{4} I_{9 / 2}$ transition is shown in Fig. 6 b by referring literature $[22,23]$. The spectra of $\mathrm{Nd}^{3+}$ in low acidity solutions $\left(0.01 \mathrm{M} \mathrm{HNO}_{3}\right.$ and $\left.\mathrm{HCl}\right)$ were almost the same and were similar to that in $\mathrm{HClO}_{4}$ solutions $[24,25]$. The spectra were clearly changed with the decrease of water content. The oscillator strength (the index for the transition probability) of the hypersensitive $f-f$ transition of $\mathrm{Nd}$ is known to be larger for stronger interaction between $\mathrm{Nd}^{3+}$ and ligands [21 and references therein]. The oscillator strength can be defined as,

$$
f=4.319 \times 10^{-9} \frac{9 n}{\left(n^{2}+2\right)^{2}} \int \varepsilon(v) d v
$$

where $\varepsilon(v)$ is the molar absorptivity at energy $v\left(\mathrm{~cm}^{-1}\right)$ and $n$ is the refractive index of the solvent medium. The $f$ value of the results shown in Fig. 6 was evaluated (Fig. 7a). The $f$ values increased with the decrease of water content for both systems. At a fixed temperature, the factors influencing $f$ are: (i) symmetry of $\mathrm{Nd}(\mathrm{III})$ complex and (ii) electron donating ability of ligands around $\mathrm{Nd}^{3+}$. The increase of $f$ shown in Fig. 7a suggests that the tricapped trigonal prism [22], which is a typical 9 hydration for lighter lanthanides, is distorted. The substitution of hydrated waters of $\mathrm{Nd}^{3+}$ by $\mathrm{NO}_{3}{ }^{-}$or $\mathrm{Cl}^{-}$ would have occurred. As shown in Fig. 6a, the intense increase of ${ }^{4} G_{5 / 2} \leftarrow{ }^{4} I_{9 / 2}$ transition 
probability of $\mathrm{Nd}(\mathrm{III})$ in $\mathrm{Ca}\left(\mathrm{NO}_{3}\right)_{2} \cdot R \mathrm{H}_{2} \mathrm{O}$ is suggestive of the substitution of hydrated $\mathrm{H}_{2} \mathrm{O}$ around $\mathrm{Nd}^{3+}$ by $\mathrm{NO}_{3}{ }^{-} \cdot f$ may have been enhanced by a direct interaction between $\mathrm{Nd}^{3+}$ and $\mathrm{NO}_{3}{ }^{-}$.

The structural studies on $\mathrm{Ca}\left(\mathrm{NO}_{3}\right)_{2} \cdot \mathrm{RH}_{2} \mathrm{O}$ by x-ray diffraction [26,27] and neutron diffraction [28] analyses have pointed out the contact ion pair of $\mathrm{Ca}^{2+}$ and $\mathrm{NO}_{3}{ }^{-}$. Their results suggest that the contact ion pair of $\mathrm{Nd}^{3+}$ and $\mathrm{NO}_{3}{ }^{-}$is also possible in $\mathrm{Ca}\left(\mathrm{NO}_{3}\right)_{2} \cdot R \mathrm{H}_{2} \mathrm{O}$. The hydration number of $\mathrm{M}^{3+}$ in $\mathrm{Ca}\left(\mathrm{NO}_{3}\right)_{2} \cdot R \mathrm{H}_{2} \mathrm{O}$ has been found to decrease with water content [29]. Hence, the changes in spectra (Fig. 6a) and $f$ (Fig. 7a) of $\mathrm{Ca}\left(\mathrm{NO}_{3}\right)_{2} \cdot \mathrm{RH}_{2} \mathrm{O}$ system would be consistent with the occurrence of contact ion pair of $\mathrm{Nd}^{3+}$ and $\mathrm{NO}_{3}^{-}$.

The spectra shown in Fig. $6 \mathrm{~b}$ do not show the drastic increase of the ${ }^{4} G_{5 / 2} \leftarrow{ }^{4} I_{9 / 2}$ transition probability of $\mathrm{Nd}(\mathrm{III})$ in $\mathrm{CaCl}_{2} \cdot \mathrm{RH}_{2} \mathrm{O}$. The reason is reported to be a weaker interaction of $\mathrm{Cl}^{-}$with $\mathrm{H}_{2} \mathrm{O}$ molecules in the inner hydration sphere of $\mathrm{Nd}^{3+}[30]$. The specific feature of Fig. $6 \mathrm{~b}$ may be the energy shift of the ${ }^{4} G_{5 / 2} \leftarrow^{4} I_{9 / 2}$ transition peak. This may be correlated with the nephelauxetic effect [31]. It is known that the red shift (depression of transition energy) is caused by the strong interaction between $f$-elements (lanthanides and actinides) and ligands [31,32]. The stronger interaction reduces the values of the free-ion parameters and causes a contraction of energy level structures of the $f$-element ions in matrix. In the present study, the spectra shown in Fig. $6 \mathrm{~b}$ were decomposed into 6 absorption peaks by Gaussian/Lorentzian sum function, and the peak position of the ${ }^{4} G_{5 / 2} \leftarrow{ }^{4} I_{9 / 2}$ transition was estimated. It should be noted that, since there are many transitions from sub-levels of ${ }^{4} I_{9 / 2}$ to sub-levels of ${ }^{4} G_{5 / 2}$ and ${ }^{2} G_{7 / 2}$ [22], the peak position (Fig. 6b) assigned to be the ${ }^{4} G_{5 / 2} \leftarrow{ }^{4} I_{9 / 2}$ transition by referring literatures 
$[22,23]$ might be interfered by the transitions between sub-levels. The parameter $\beta=$ $v_{\text {sample }} / v_{\text {reference }}[23,31]$, where $v$ is the wavenumber $\left(\mathrm{cm}^{-1}\right)$ at the ${ }^{4} G_{5 / 2} \leftarrow{ }^{4} I_{9 / 2}$ transition, was determined. The subscript "reference" means $0.01 \mathrm{M} \mathrm{HNO}_{3}$ for nitrate systems or $0.01 \mathrm{M} \mathrm{HCl}$ for chloride systems. Figure $7 \mathrm{~b}$ shows $1-\beta$ as a function of $a_{\mathrm{H}_{2} \mathrm{O}}$. The $1-$ $\beta$ value increased with the decrease of $a_{\mathrm{H}_{2} \mathrm{O}}$. This means that the red shift occurs with the decrease of water content. This trend is consistent with a report on $\mathrm{Nd}^{3+}$ in concentrated $\mathrm{LiCl}[23]$.

Structural studies on $\mathrm{CaCl}_{2} \cdot 6 \mathrm{H}_{2} \mathrm{O}$ by x-ray diffraction $[33,34]$ showed that $\sim 1$ $\mathrm{Cl}^{-}$ion exists in the first hydration sphere of $\mathrm{Ca}^{2+}$. Their results suggest that the contact ion pair of $\mathrm{Nd}^{3+}$ and $\mathrm{Cl}^{-}$is possible in $\mathrm{CaCl}_{2} \cdot \mathrm{RH}_{2} \mathrm{O}$. In a study on $\mathrm{Nd}^{3+}$ in concentrated $\mathrm{LiCl}$ solutions, it was suggested that, with the decrease of water content, the hydrated $\mathrm{H}_{2} \mathrm{O}$ around $\mathrm{Nd}^{3+}$ is substituted by $\mathrm{Cl}^{-}$and the coordination number decreases from 9 to 8 [23]. Since the electron donating ability of $\mathrm{O}$ in $\mathrm{H}_{2} \mathrm{O}$ is different from that of $\mathrm{Cl}^{-}$, varying the water content changes the ligand field around $\mathrm{Nd}^{3+}$ and this may have caused the shift in peak position shown in Fig. $6 \mathrm{~b}$ and also the increase of $f$ (Fig. 7a).

The correlations $f v s . \log a_{\mathrm{H}_{2} \mathrm{O}}$ and $1-\beta v s . \log a_{\mathrm{H}_{2} \mathrm{O}}$ (Fig. 7) possess similar trends of $\frac{1}{4}\left(\log D_{\mathrm{Am}}-3 \log \left[\mathrm{X}^{-}\right]\right)$vs. $\log a_{\mathrm{H}_{2} \mathrm{O}}$ shown in Fig. $4 \mathrm{~b}$. However the inflection property shown in Fig. 7a and $7 b$ is not clear compared with that shown in Fig. 4b. This suggests that the inflection depends not only on the short distance as the first coordination sphere of $\mathrm{M}^{3+}$ but also the long distance like second and far coordination spheres. 


\section{Conclusions}

Coordination characteristics of trivalent lanthanides and actinides in hydrate melts were investigated by solvent extraction method and spectrophotometry. In PUREX experiments, distribution behavior of trivalent lanthanides and actinides in water deficient system was different from that in water abundant system. Contact ion pairing of trivalent $f$-elements with anions in inorganic phase occurs with the decrease of water content, and the coordination circumstance change would result in the change of distribution behavior. The distribution behavior may also be affected by changes in far coordination spheres.

\section{Acknowledgment}

The authors wish to thank Roy Jacobus for his help in improving the English expressions of this paper. A part of this study is result of "Basic actinide chemistry and physics research in close cooperation with hot laboratories" carried out under the Strategic Promotion Program for Basic Nuclear Research by the Ministry of Education, Culture, Sports, Science and technology of Japan.

\section{References}

[1] Aratono Y, Akatsu E (1974) J Inorg Nucl Chem 36:1141

[2] Mitsugashira T, Kamoshida M, Suzuki Y, Satoh I (1994) J Alloys Compd 213-214:347

[3] Yamana H, Kaibuki T, Miyashita Y, Shibata S, Moriyama H (1998) J Alloys Compd 271-273:707

[4] Yamana H, Kaibuki T, Moriyama H (1999) Radiochim Acta 84:191 
[5] Fujii T, Yamana H, Moriyama H (2001) J Nucl Sci Technol Suppl 3:336

[6] Yamana H, Asano H, Fujii T, Gohtoh R, Moriyama H (2002) Radiochim Acta. $90: 87$

[7] Okude G, Fujii T, Uehara A, Sekimoto S, Minato K, Yamana H (2010) IOP Conf Ser: Mater Sci Eng 9:012067

[8] Akatsu E, Asano M (1971) Anal Chim Acta 55:333

[9] Hesford E, Jackson EE, MCKay HAC (1959) J Inorg Nucl Chem 9:279

[10] Best GF, Hesford E, M Kay HAC (1959) J Inorg Nucl Chem 12:136

[11] Marcus Y (1985) Ion solvation. John Wiley \& Sons, Chichester

[12] Suhotina AM (1981) Databook of electrochemistry. Leningrad, Leningrad Chemistry

[13] Ewing WW, Mikovsky RJ (1950) J Am Chem Soc 72:1390

[14] Lide DR (2008) Handbook of chemistry and physics, 89th ed. CRC Press, Boca Raton

[15] Nash KL (1994) In: Gschneidner KA, Eyring LeRoy, Choppin GR (eds) Handbook on the physics and chemistry of rare earth. Elsevier, Amsterdam

[16] Mirvaliev R, Watanabe M, Matsumura T, Tachimori S, Takeshita K (2004) J Nucl Sci Technol 41:1122

[17] Chen J, Veltkamp AC, Booij AS (2002) J. Radioanal Nucl Chem 253:31

[18] Stary J (1966) Talanta 13:421

[19] Peppard DF, Faris JP, Gray PR, Mason (1953) J Phys Chem 57:294

[20] Sanchez-Ocampo A, Lopez-Gonzalez H, Jimenez-Reyes M (1991) J Radioanal Nucl Chem 154:435

[21] Yatsimirskii KB, Davidenko NK (1979) Coord Chem Rev 27:223 
[22] Rajnak K, Couture L (1981) Chem Phys 55:331

[23] Khripun MK, Efimov AYu, Chervonenko KYu (1993) J Struct Chem 34:267

[24] Moeller T, Ulrich WF (1956) J Inorg Nucl Chem 2:164

[25] Karraker DG (1968) Inorg Chem 7:473

[26] Caminiti R, Musinu A, Paschina G, Piccaluga G, Pinna G (1981) Z Naturforsch 36a:831

[27] Smirnov P, Yamagami M, Wakita H, Yamaguchi T (1997) J Mol Liq 73-74:305

[28] Igarashi K, Tajiri K, Asahina T, Kosaka M, Iwadate Y, Mochinaga J (1993) J Mater Sci 18:2774

[29] Fujii T, Asano H, Kimura T, Yamamoto T, Uehara A, Yamana H (2006) J Alloys Compd 408-412:989

[30] Choppin GR, Henrie DE, Buijs K (1966) Inorg Chem 5:1743

[31] Jørgensen CK (1959) Mol Phys 2:96

[32] Barbanel' YuA, Kolin VV, Kotlin VP, Lumpov AA (1990) J Radioanal Nucl Chem 143:157

[33] Yamaguchi T, Hayashi S, Ohtaki H (1989) Inorg Chem 28:2434

[34] Fulton JL, Heald SM, Badyal YS, Simonson JM (2003) 107:4688 


\section{Figure captions}

Fig. 1 Water activities in $\mathrm{Ca}\left(\mathrm{NO}_{3}\right)_{2} \cdot R \mathrm{H}_{2} \mathrm{O}$ and $\mathrm{CaCl}_{2} \cdot R \mathrm{H}_{2} \mathrm{O}$ at $343 \mathrm{~K}$. Open marks were literature values [12]. $a_{\mathrm{H}_{2} \mathrm{O}}$ of solid marks was estimated in the present study by using an electric hygrometer (Novasina IC-500, AW-LAB).

Fig. 2 Distribution ratios of $\mathrm{Am}, \mathrm{Cm}$, and $\mathrm{Eu}$ between $\mathrm{Ca}\left(\mathrm{NO}_{3}\right)_{2} \cdot \mathrm{RH}_{2} \mathrm{O}$ and PUREX solvent. a) Dependence of $\log D$ on $\log a_{\mathrm{H}_{2} \mathrm{O}} . D_{\mathrm{Am}}, D_{\mathrm{Cm}}$, and $D_{\mathrm{Eu}}$ measured in our previous study [6,7] were reproduced as functions of $a_{\mathrm{H}_{2} \mathrm{O}}$ obtained in the present study. Experimental conditions are $[\mathrm{TBP}]=0.02 \mathrm{M}$ and $T=343 \mathrm{~K} . \mathrm{b}$ ) Dependence of $\log D$ on $\log$ [TBP]. $1 \sigma$ errors due to $\gamma$-analysis are shown together. The inorganic phase is $\mathrm{Ca}\left(\mathrm{NO}_{3}\right)_{2} \cdot 4 \mathrm{H}_{2} \mathrm{O}$ and experimental temperature is $T=343 \mathrm{~K}$.

Fig. 3 Separation factors of Eu/Am and $\mathbf{C m} / \mathbf{A m}$. a) Dependent of separation factor on $\log a_{\mathrm{H}_{2} \mathrm{O}} \cdot D_{\mathrm{Eu}} / D_{\mathrm{Am}}$ and $D_{\mathrm{Cm}} / D_{\mathrm{Am}}$ were calculated from fitting curves shown in Fig. 2a. b) Dependence of separation factor on $\log [\mathrm{TBP}] . D_{\mathrm{Eu}} / D_{\mathrm{Am}}$ was calculated from data shown in Fig. 2b. Error bars of $D_{\mathrm{Cm}} / D_{\mathrm{Am}}$ are attributable to errors of $D_{\mathrm{Am}}$ and $D_{\mathrm{Cm}}$.

Fig. 4 Distribution ratios of $\mathrm{Am}$ between $\mathrm{CaCl}_{2} \cdot R \mathrm{H}_{2} \mathrm{O}$ and PUREX solvent. a) $D_{\mathrm{Am}}$. $D_{\text {Am }}$ between $\mathrm{Ca}\left(\mathrm{NO}_{3}\right)_{2} \cdot R \mathrm{H}_{2} \mathrm{O}$ and PUREX solvent (Fig. 2a) is shown together. b) $\frac{1}{4}\left(\log D_{\mathrm{Am}}-3 \log \left[\mathrm{X}^{-}\right]\right) \cdot \mathrm{X}^{-}$means $\mathrm{NO}_{3}{ }^{-}$and $\mathrm{Cl}^{-}$. Details of derivation can be seen in Eqs. 3-6.

Fig. 5 Distribution ratios of $\mathrm{Eu}$ between $\mathrm{CaCl}_{2} \cdot 6 \mathrm{H}_{2} \mathrm{O}$ and PUREX solvent with various [TBP].

Fig. 6 Electronic absorption spectra of hypersensitive transition of $\mathrm{Nd}(\mathrm{III})$ in hydrate melts. The absorption spectra are measured at room temperature. a) 
$\mathrm{Ca}\left(\mathrm{NO}_{3}\right)_{2} \cdot R \mathrm{H}_{2} \mathrm{O}$. b) $\mathrm{CaCl}_{2} \cdot R \mathrm{H}_{2} \mathrm{O}$.

Fig. 7 Oscillator strength of hypersensitive transition and shift in peak position for absorption spectra of $\mathrm{Nd}(\mathrm{III})$ in hydrate melts. a) Oscillator strength of the ${ }^{4} G_{5 / 2},{ }^{2} G_{7 / 2} \leftarrow{ }^{4} I_{9 / 2}$ transition. The $f$ values (Eq. 7) are shown as functions of $a_{\mathrm{H}_{2} \mathrm{O}} \cdot \mathrm{b}$ ) Energy shift of the ${ }^{4} G_{5 / 2} \leftarrow{ }^{4} I_{9 / 2}$ transition peak for $\mathrm{Nd}^{3+}$ in $\mathrm{CaCl}_{2} \cdot \mathrm{RH}_{2} \mathrm{O}$. The absorption spectra shown in Fig. $6 \mathrm{~b}$ were decomposed into 6 absorption peaks by Gaussian/Lorentzian sum function, and the peak position of the ${ }^{4} G_{5 / 2} \leftarrow{ }^{4} I_{9 / 2}$ transition was estimated referring literatures [22,23]. The $1-\beta$ value (see text) is shown as a function of $a_{\mathrm{H}_{2} \mathrm{O}}$. 


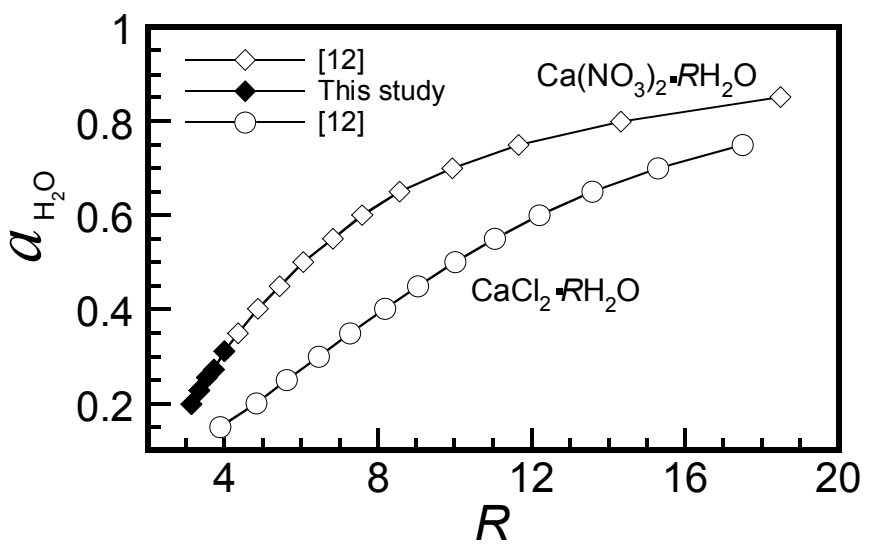

Figure 1 (Fujii et al.) 

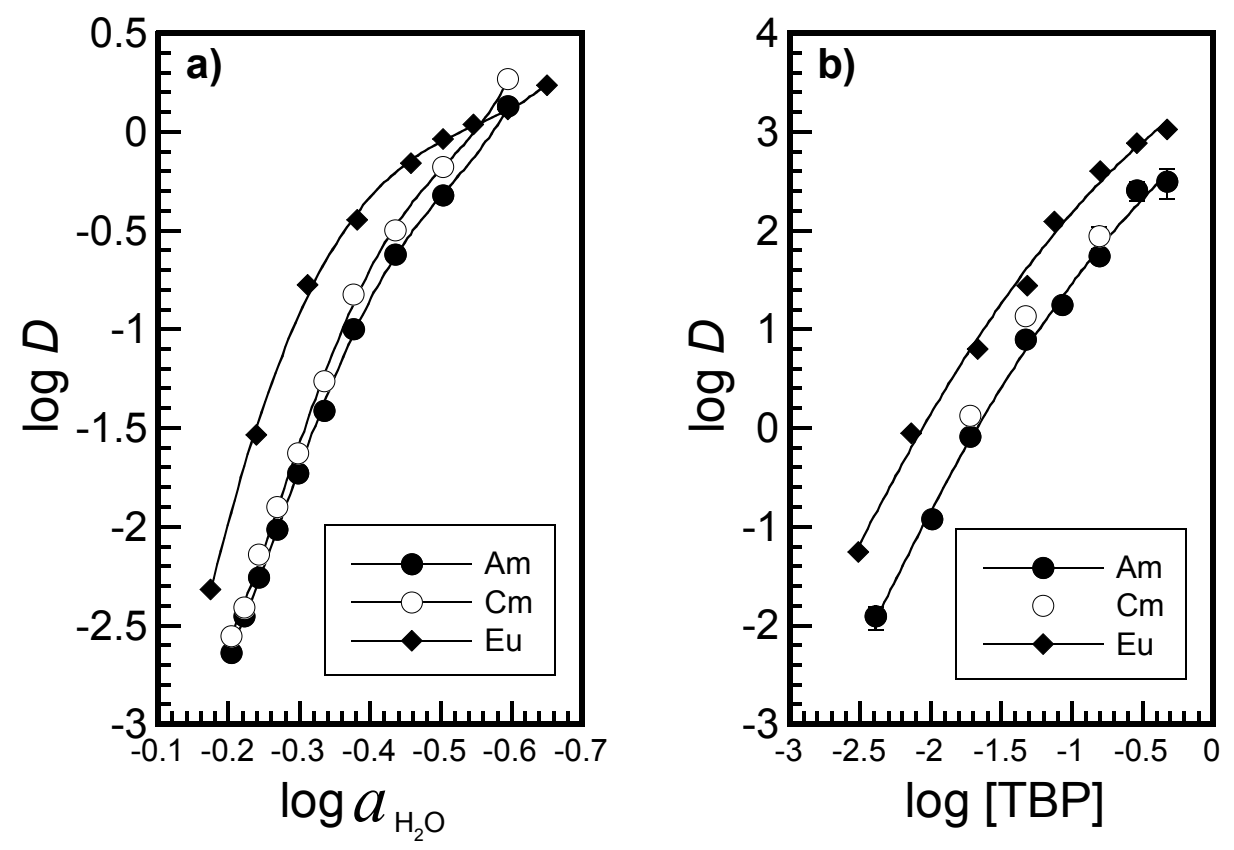

Figure 2 (Fujii et al.) 

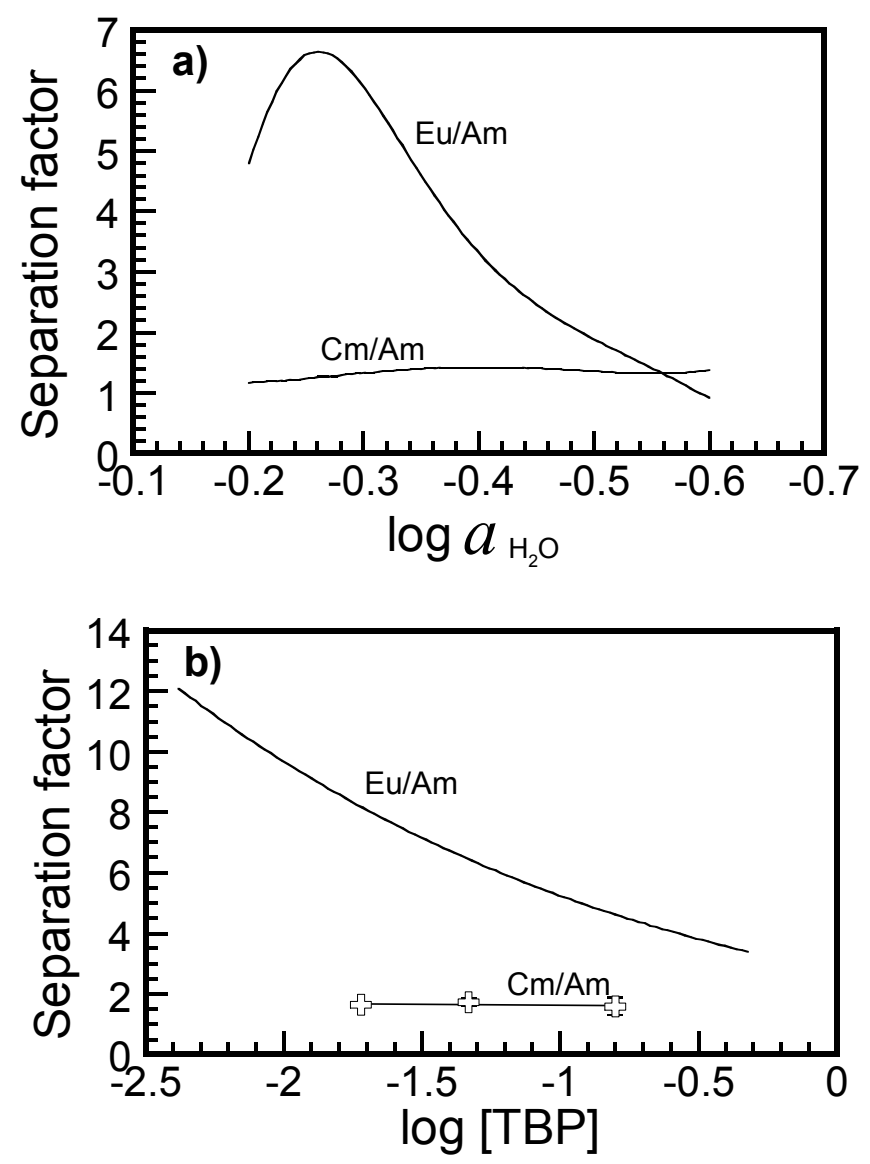

Figure 3 (Fujii et al.) 

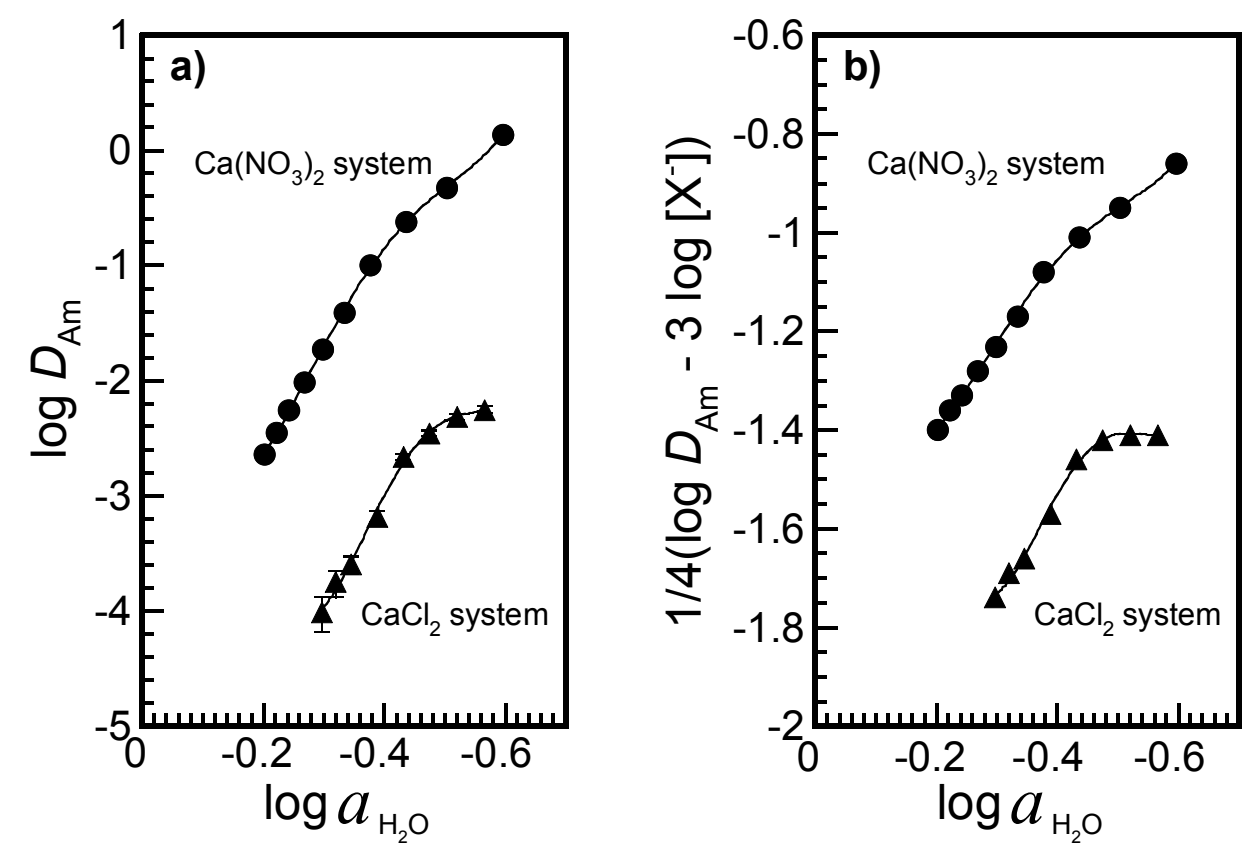

Figure 4 (Fujii et al.) 


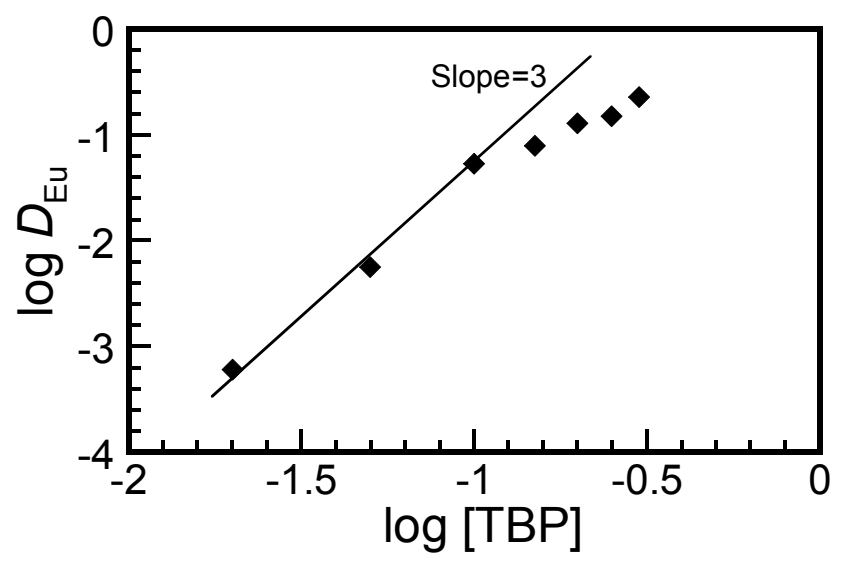

Figure 5 (Fujii et al.) 

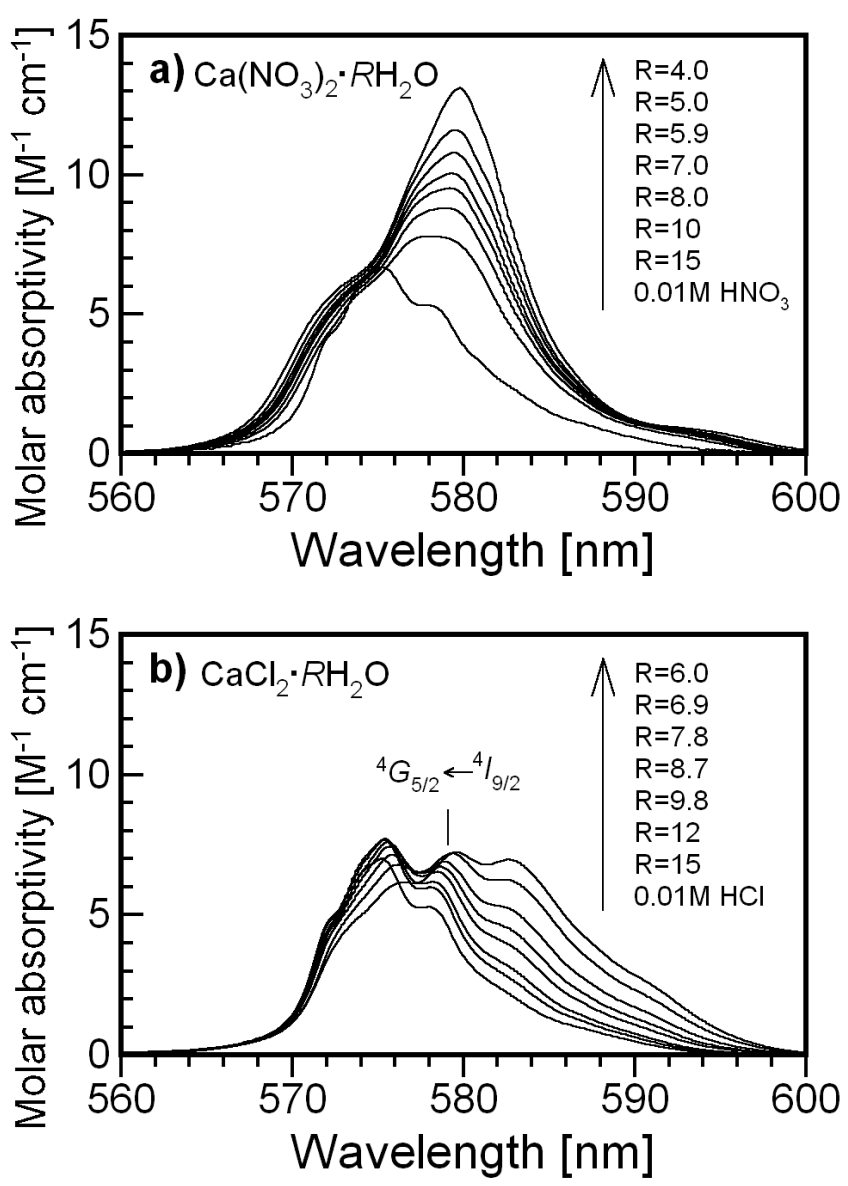

Figure 6 (Fujii et al.) 

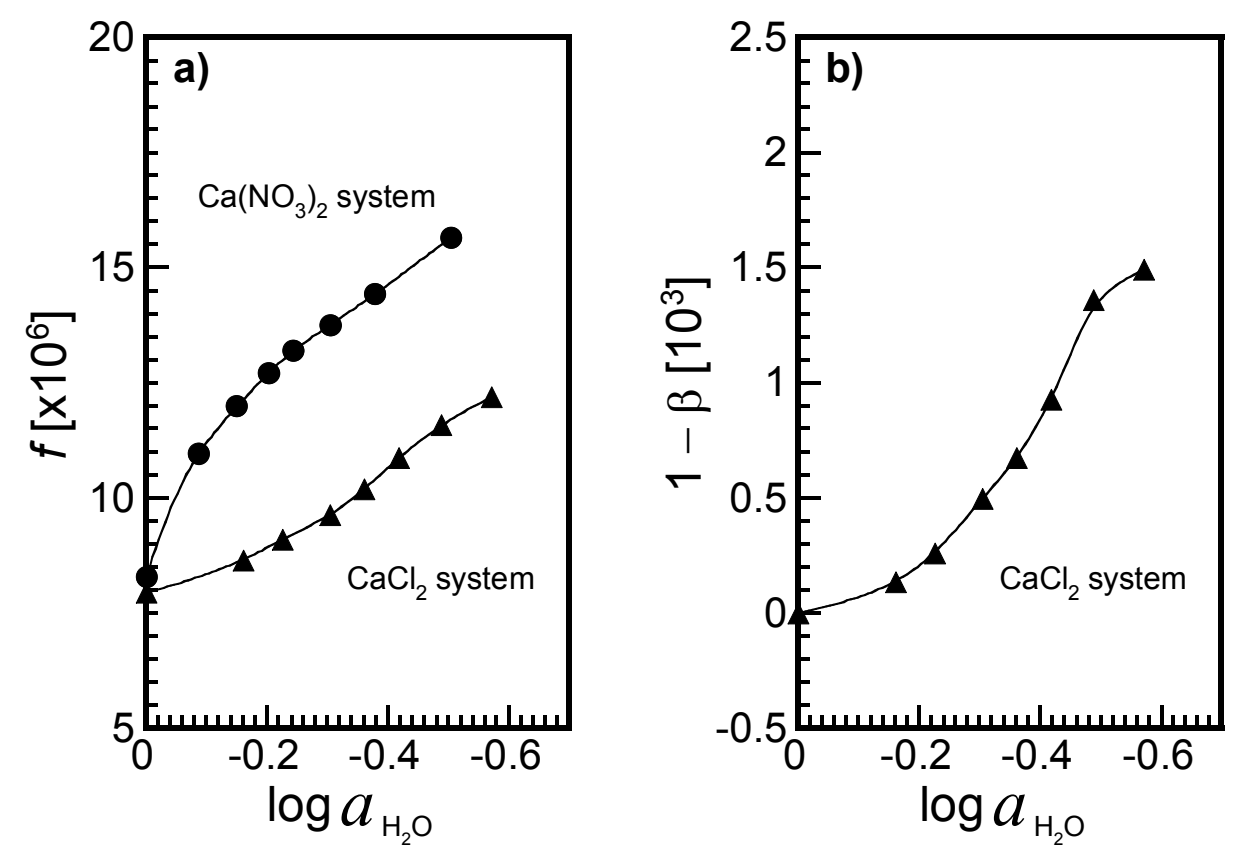

Figure 7 (Fujii et al.) 